\title{
Managing Communication in Knowledge-Intensive Service Teams: Groupthink Theory Revisited
}

\author{
Cigdem Sahin \\ Dept. of New Media and Communication, Uskudar University \\ Haluk Turksoy Cd. No:15 Altunizade, Uskudar, Istanbul, Turkey \\ Tel: 90-216-400-2222Ｅ-mail: cigdem.sahin@ uskudar.edu.tr
}

Received: August 28, 2014 Accepted: September 5, 2014 Published: December 26, 2014

doi:10.5296/bms.v5i2.6233 URL: http://dx.doi.org/10.5296/bms.v5i2.6233

\begin{abstract}
Changing organizational structures of new service firms, especially knowledge intensive services (KIS) which have become more complicated and diversified in recent years require better organizational communication. This study points out that team management and communication in KIS have some special characteristics and should be discussed in line with the theory of Groupthink. The present paper contributes that leadership and organizational culture are very important antecedent conditions for groupthink in KIS teams, and require further investigations. Along with examining the advantages and disadvantages of presented solutions to avoid groupthink incidences, this paper also provides implications for practice.
\end{abstract}

Keywords: Organizational communication, Knowledge-intensive services, Groupthink, Leadership, Organizational culture 


\section{Introduction}

High growth of internationalization and diversification of service business in recent years oblige managers to find new and better ways for effective team management. Because most services are highly intangible and are not easy to be standardized, customers' assessment of service quality is more important issue for services than for any other businesses. Effective team management in services depends more on enriching communication, harmony and empathy among people through minimizing wrong decisions and misunderstandings since a major part of most service processes includes human interaction.

Today, many multinational services have become networked organizations and need to manage their organizational communication better. Their organizational structure is more complicated and diversified than before, so is their organizational communication such as communication within a local subsidiary, among different subsidiaries, subsidiaries to parenting firm or among regional subsidiaries, etc. In addition to conventional communication methods, digital technology enables firms to manage their works and communications through SMS technologies, e-mailing, tele-conferencing, video-conferencing, social media tools and so on. Therefore, there are various communication mediums to be used and alternative techniques to adapt for a successful communication inside an organization. On the other hand, multinational firms aim to apply a "seamless communication" strategy throughout their networks that will help to standardize their works and increase service quality which will lead to higher customer satisfaction rates. Conclusively, management of teams and communication is getting harder for services that are primarily based upon their employees' collected knowledge and skills.

The extant literature has so far mainly focused on diversity and conflict in teams and provided suggestions for increasing congruity among team members. However, cohesiveness and consistency in teams may also be problematic, and need to be carefully managed. Especially start-up entrepreneurial companies, e-commerce companies, creative agencies, software companies, healthcare services etc. which are mostly knowledge-based focus on providing innovative ideas or customized products/services for their specific group of customers. This "value added" knowledge generated within groups is generally resulted from strong argumentative discussions, brainstorming sessions, playing devil's advocate, etc. Developing counter-arguments in discussions enriches knowledge and empathy among team members and increases success of team decisions. Therefore, such attempts to increase consistency among work groups may cause to failures and inhibit development of unique customer solutions which can be the main competitive advantage of any kind of services.

Here, this study argues that management of agreement in teams should be discussed further in services context since they have been diversified and restructured due to the advances in technology and internationalization. The main focus will be on knowledge-intensive services which are ranging from healthcare to creative industries and have been increasing their weights in the new economy (Zieba, 2013). Therefore, the well-known theory for group cohesiveness, Groupthink has been revisited within knowledge intensive services perspective. 
The paper contributes to the groupthink research by highlighting the changing roles of leadership and organizational culture at knowledge intensive services.

\section{The Theory of Groupthink and Knowledge Intensive Services}

The theory of groupthink requires special attention in knowledge intensive services (KIS) because it is one of the rare theories focusing on team communication and demonstrating how "good-looking" teams may work badly and what the consequences of their failures are. Since managing diversity and conflict in teams are emerging issues to study in the context of knowledge intensive services in general, it is also important to know that managing agreement can be a big concern.

Knowledge-intensive services (KIS) can be defined as services whose main activity depends on producing and delivering "special knowledge" to their clients whom they have intensive interactions. For these services, knowledge, as both an input and an output, can generate sustainable competitive advantage and thereby is the most important resource of all. Team management is particularly important for knowledge-intensive services which generally consist of several teams to accumulate, generate and transform knowledge based on collected knowledge and experiences of their own. Because what they produce is a combination of both tacit and codified knowledge for specific needs of their clients, team members in knowledge intensive services need to work closely together in a way that triggers their individual knowledge and skills to produce something new and valuable. If a team process does not work well, then a valuable output cannot be expected and conclusively good relations with clients whom are highly difficult to attain and very easy to be lost cannot be maintained (Lowendahl, 2000; Liu, 2013).

Knowledge intensive services include knowledge-intensive business services (KIBS), and innovative services dedicated to develop new products or services (Haataja \& Okkonen, 2004). Such KIS as healthcare providers, banking firms, software companies, law firms, advertising firms, research firms, educational and consulting firms, etc. are formed by special groups of highly skilled and knowledgeable people who are devoted to produce effective solutions to customers' specific business problems. It is their specialized knowledge that generates the most important competitive advantage of a firm (Løwendahl, 2000). Therefore, any failure when elaborating knowledge and information in decision-making could be much more disastrous for KIS than any other business.

Groupthink has become one of the most well-known theories explaining conditions preceding the misbehavior of groups, and it has been studied by researchers from several disciplines, such as politics, organizational management, social psychology, and communication. In 1972, Janis conceptualized that cohesive groups face with repeated manifestation of the effects of the social pressures. He defined the phenomena as "Groupthink" that is "a mode of thinking that people engage in when they are deeply involved in a cohesive in-group, when the members' strivings for unanimity override their motivation to realistically appraise alternative courses of action" (Janis,1972, p.9). According to him, groupthink refers to "a deterioration 
of mental efficiency, reality testing, and moral judgment that result from in-group pressures" (Janis, 1972, p.9).

Groupthink can lead to bad judgments and decisions because members of group tend to give a decision before taking all possible actions into account. After examining several failures of governments in political and military issues (The bay of pigs-Kennedy period, Vietnam-Johnson period, Watergate, Nixon period, and Korean War), Janis found out why intelligent groups of people sometimes made decisions that caused to disastrous results. The groups in all examples were suffering from groupthink, because they were highly cohesive, and sharing a strong "wefeeling" of solidarity and desiring to maintain relationships within the group at all costs" (Janis, 1972, pp.11-12).

However, not all cohesive groups suffer from groupthink. The group's "nomothetic characteristics" and its situational context could more likely to be the causes of small group decision failures than the individualistic collection of personalities of group members. Even members of a group who have high self-esteem, and can act independently, might be affected by group atmosphere, and conform to the group. All these features would create antecedent conditions that lead to concurrence-seeking within groups. Then, symptoms of groupthink may be observed and in result, they lower the probability of good decision making (Miranda \& Saunders, 1995).

There are three types of group antecedents described for groupthink. Cohesiveness is the strongest antecedent condition in formulating groupthink situations which indicates the degree of consensus among members. Cohesive groups of highly qualified, experienced individuals believe that everyone in the group agrees with the group judgments. However, the negative effects of false consensus may lead to problems in group decisions (Von Bergen, Sopher \& Masters, 2001).

The second type of group antecedents are called as Structural Antecedents that involve four important factors (Miranda \& Saunders, 1995, p.197):

\section{Insulation of the group experts and opinions outside the group}

When the group is isolated, it does not require gaining ideas from outsiders and gives the decision by them. Without the opinions of outsiders, it's very easy to fall into illusions of group invulnerability and morality. This is especially the case for many firms in creative industries. Creative groups are formed to work together for specific clients groups for a long period of time, such as a creative group may consist of a creative head, an art director and a copy writer in an advertising agency. Sooner, especially after gaining some awards and recognitions, they may develop a sense of invulnerability that can damage their objectivity and their strength of minds (Antonietti \& Cainelli, 2007). In addition, groups may fail to examine the possible risks of choice preferred by majority. The members isolate themselves from outside and make little or no attempt to get information from experts to reassess their decision. Even if they expose to actual information coming from experts from outside and mass media, they may distort or misinterpret the messages. 
Thus, group members of KIS are more likely to feel illusion of invulnerability. Particularly for the group of people working together for a long time, confidence among the members of the group would be higher (Haas \& Banerjee, 2008).

\section{Lack of tradition of impartial leadership}

Leaders can control the group processes and have greater influences than other members. If a strong leader exists in the group discussion and always gives his opinions clearly, it's likely the group discussion will be limited or controlled. In contrast, the group members hide their own opinions and conform on leader's decision due to the pressure.

Fear of being rejected is stated as the main cause to obey a group decision (Janis, 1982). Also members tend to censor their own thoughts that are challenging with group ideas. This is an unpleasant situation for KIS, especially in creative industries in which the most valuable outcome is expected to be produced as a result of strong debates, arguments and conflicts. If dissenters within the group are pressured into conformity it would be more likely that group will be a victim of groupthink. In the next section, leadership and importance of managerial knowledge in KIS will be elaborated in more detail.

\section{Lack of norms requiring methodical procedures}

If the decision making procedure is unsystematic, for example, the decision is made by the leader of the team based on his preference but not the result of a discussion, it may also cause groupthink. If the procedure of reviewing decision does not exist, it will cause a problem because there is no chance for members to judge the decision again after the decision has been made. This is also related with organizational culture that defines how things are done in work places, and will be examined in detail in the next sections.

\section{Homogeneity of members' social background and ideology}

A group consist of homogeneous members will have similar background such as education and culture so that their way of thinking might be also similar. At last, their solution to the issues might be the same; the group thought would be limited and ineffective. Therefore, selection of people in teams from different social and intellectual backgrounds could be a solution, but then their management becomes a very delicate issue. Especially for KIS, it is highly problematic because they have well-educated, highly qualified and skilled employees who are more likely to have similar values and lifestyles. On the other hand, these people use heavily social media which also unifies them by setting their agendas on what to think about and shaping their opinions and feelings toward some certain issues or events.

The third type of antecedents is called as Task Types of the group. According to Janis (1972), people that have challenging tasks are more likely to be victim of groupthink When a group is under stress, assuming that time is limited to make an important decision, the person who makes this decision will feel insecure and attempts to find any reassuring support of other group members. Somehow, group will also reassure the decision in order to reduce stress. 
Then it may lead to a situation that everyone agrees on the decision without any disagreement.

Knowledge-intensive service firms are more project-oriented and work heavily based on tight schedules. Although customers' value-added solutions are delivered by highly sophisticated and well-educated people, creation of these solutions may not always be easy when thinking time pressures, the other projects involved, managerial interventions, financial obligations, etc. Hence, group cohesiveness may be more observable at KIS than in any other businesses.

\section{The Effects of Leadership on Groupthink}

Leadership is one of the widely debated issues in groupthink studies as well as in KIS research. Level of a leader (top level or middle level) as well as his/ her leadership characteristics can affect teams in their decision making. Haas \& Banerjee (2008) emphasized the role of leader in a team's decision making process that type of a leader changes whole methodological way of producing a solution to a given problem. Leana (1985) also stated that leader behavior and cohesiveness are group level constructs (differing from other variables in sense of their individualistic characters) that distinguish groupthink as a group rather than individual phenomenon.

Neck \& Morrhead (1995) noted that leaders must encourage others to challenge their thinking. If the team leader is at least as senior as others in the group, leadership is enhanced. However, if the leader is too senior, participation decreases and the value of the group's different views become rare and groupthink occurs. Top management teams who are more creative and agile in problem solving are rarely become victims of groupthink (Berdie, 2003; Carpenter \& Fredrickson, 2001)

Furthermore, Chen \& Lawson (1996) supported Janis theory that groups with directive leaders come up with lower quality decisions. They concluded that good leaders should possess openness in discussions to obtain a variety of alternatives for problem solutions. Closed leadership style characterizes an ineffective team leader who promotes groupthink. He does not give encouragement for member participation, and states his personal opinion at the beginning of the meeting. Because he does not favor to collect divergent opinions from all group members, it is very unlikely to reach a wise decision in those groups. On the other hand, an effective team leader is the one who serves as a consultant, advisor, and a facilitator, establishes a climate in which people can express their ideas, get empowerment to work on final decision. Today this is called as open-style leadership (Schaeffer, 2002) or transformational leadership (Kozlowski \& Ilgen, 2006) corresponds the promotional leadership term used by Janis in 1972.

According to Janis (1972), open-leadership style encourages flow of different and counter ideas in discussions and seeks for alternative ways for actions, therefore should prevent tendency of concurrence-seeking and reaching to wrong decisions. Alvesson (2004) stated that KIS are different from other traditional firms because they require limited management and control over their employees who are highly educated, skilled and used to work 
independent and with high empowerment. Therefore, in these firms, open leadership style should have been expanded with necessary skills to manage and retain this type of employees. If a KIS loses an employee, it would not loose just a personnel but an important part of its production and service delivery process that would be highly costly to replace.

Although their roles are seen somewhat limited in KIS (Alvesson, 2004), leaders are their fundamental parts, especially of those in creative and consultancy sectors. Here, leaders, in most instances they are also founders, are seen like guru, set organizational philosophies, shape relations with clients and other stakeholders, endorse teams and services and help to build positive image and reputation about their firms. Their knowledge gained through experiences of long years in practice forms a base for teams in discussions and has a certain influence on team decisions. This is neither just an open style leadership nor a limited one; this is a different style leadership which is highly influential, transformational and supportive. When thinking such KIS leaders as Leo Burnett, David Ogilvy, Steve Jobs, Larry Page \& Sergey Brin, etc. the importance of leadership for KIS could be clearer.

Janis examined style of leadership as one of the variables of antecedent conditions for groupthink in his original model in 1972. The antecedents of groupthink may lead to symptoms if only a closed leadership style was adopted. However, open-leadership style may not be easily adopted and applied, and not always reveal positive outcomes. Woodruff (1991) reported that too much encouragement and praise may lead to underestimation of the problems; therefore may create a symptom for groupthink. Open-leaders should be careful when distributing power and control over issues. Because most KIS today are networked organizations their leaders with geographically scattered teams have to build diverse skills comparing to those with traditional, co-located teams. They could be able to use different kinds of skills based on the diversity of their team members and the distance between them (Meyer, 2010).

\section{Groupthink and Organizational Culture}

Organizational culture is formed by values and beliefs of an organization reflected by organizational behavior (Cameron \& Quinn, 2011). These values and beliefs are explicitly defined as vision and mission statements of an organization. Some organizations foster individualism, competition, entrepreneurship while some highlight solidarity, coordination and team-mating. The culture in which a firm belongs shapes its values and beliefs, thereby its organizational culture. Even multinational firms try to adapt themselves in host country conditions and respect their values and beliefs in order to survive in these markets.

According to Hofstede (2001), cultures can be distinguished by their level of individualism. Individualism is defined as "the degree of individual independence" and is used as the antonym of collectivism, which emphasizes the importance of groups and social loyalty. During team processing, some members may have self-interest dilemma and stay in-between the group's and their personal interests. Team members from highly collectivistic cultural backgrounds see that their team's needs are more important than their own. Therefore, 
collective culture has an impact of reducing the potential negative impact of the self-interest dilemma. Therefore, it may be concluded that groupthink is more likely to develop in groups with collective cultural orientations than with individualistic cultural orientations.

Particularly in networked KIS, most teams are comprised of individuals from both individualistic and collectivistic countries. Therefore, leaders must pay attention to cultural differences of their team members. Creating heterogeneous groups may work well to avoid groupthink symptoms however management of effective communication inside these groups is getting difficult in multinational networks (Haas \& Banerjee, 2008).

There are various classifications for organizational culture in the literature. The model developed by Cameron \& Quinn (2006) not only classifies organizational cultural types, but also compares them in a way to be used to assess organizational effectiveness. According to this framework, there are four different cultures, such as clan, hierarchical, adhocracy, and market cultures. Knowledge-intensive services inherently adopt adhocracy cultures in which employees have great flexibility and freedom to develop new ideas and make innovations. As exampled at Google and Microsoft, this type of culture encourages people to take risks and try finding new methods or tools to do business. In adhocracies, all members of an organization have the authority within their areas of specialization, without any hierarchy among themselves (Cameron \& Quinn, 2011). Therefore, in this type of firms, coordination instead of leading is more an appropriate term. Adhocracies can only be managed by means of effective open communication inside so that establishment of teams and management of cohesiveness are highly important for KIS.

An important task for leaders of multinational KIS teams is to identify their styles of decision-making that may be rooted in the cultures that they belong to. Multinational KIS teams therefore should be directed by clear descriptions of how decisions are taken in the organization. KIS leaders should also demonstrate their ability to apply different kinds of decision-making processes at different points in a project (Meyer, 2010)

Increasing mobility and flexibility in working hours due to digital technology provide several opportunities for services to make rescheduling and outsourcing their workloads and to redesign their organizational structures. Because most KIS are project-oriented, they may implement their projects by creating virtual teams that are able to work out of office. They make contracts with their employees on a project-basis and even they may outsource some of their works to more efficient teams in a different country by using the advantages of time differences between countries Thereby, they can gain important scale economies.

However, digital communication is not found as reliable as traditional, face to face communication. Meyer (2010) stressed that one of the most important things to succeed with these virtual teams is to augment digital, distant communication by using body language. Especially managers, who try to get a serious look by sitting firmly at their desks while connecting through Skype or videoconferencing, may lose their interactive or persuasive power. When speakers act natural and move their body parts (arms, hands, head, etc.) while 
speaking, it may increase their voice quality, and then in return enhance reliability of communication.

\section{How to Avoid From Groupthink? Some Considerations}

One of the most acknowledged solutions to avoid groupthink is to assign each member of the group a "critical evaluator" to play "devil's advocate". Group members may try to find problems in group's solutions by examining them individually. However, group members can spend too much time arguing when there is an important deadline. Group members may not feel comfortable and secure when their thoughts are criticized. In addition, some group members may not have the skills to make critical evaluations about the presented solutions (Mitchell \& Eckstein, 2009; Miranda \& Saunders, 1995).

Leaders must avoid biases and stay neutral. If they lead the group to reach an expected certain outcome, group members tend to be silent which is often misinterpreted as acceptance. Everyone seems like in agreement in surface but there may be hidden thoughts kept away from the group (Janis, 1982; Ahlfinger \& Esser, 2001). However, it does not mean that leaders will have their own agenda and be decisive about implementing their projects, as they wish. If group members are not sure of what the leader wants, they may not attempt to conform to beliefs of the leadership, and start questioning the leadership. This is a common problem particularly for KIS which requires extensive managerial skills to lead a group of highly skilled and highly sophisticated people. If they believe that they are not actively included in decision making process, they may believe that their skills are underutilized, and they are underestimated as a group which may lead to collective turnover (Hausknecht \& Trevor, 2011).

In order to avoid groupthink, several different groups led by separate leaders can be assigned to work on the same problem or project. For example, advertising agencies apply this strategy when they have an important pitch in order to increase their possibility to reach a better solution and to avoid groupthink symptoms. However, when there are many people involved, information is more likely to leak out, so that security can be a problem. Problems also arise when a group assumes that the other group is working on the solution already. They may not push harder enough and let the others to complete the task. When only one group is working on a particular problem, these problems may not be seen, but the group is more likely to open groupthink threats (Von Bergen, et al., 2001). Janis suggested that all working groups can eventually come together and discuss ideas to avoid to be locked into one solution (Janis, 1972).

Another solution may be assigning an external expert. The experts need to be very qualified and skilled in their ability to sort through and analyze solutions of the group. However, it is a rare situation that experts become a part of the group before a general consensus is reached among all group members. It takes some time for a group to accept an outsider expert to involve with their works. The experts must have good communication skills to turn people into the right direction (Baron, 2005). In some multinational services, expatriates play 
important role as experienced outsider who have accumulated tacit knowledge. They are expected to bring a new perspective to discussions and to play devil's advocate.

In multinational companies, team processes mainly rely on reproducing explicit knowledge which requires following certain rules and standards. Although it eases to make all subsidiaries incorporated in terms of servicing, finding an innovative solution by using explicit knowledge could be a rare instance. Here, tacit knowledge resides in expatriates are important and therefore they are seen as knowledge brokers in networked organizations where flow of explicit knowledge could be more observed than tacit knowledge. KIS generally sell business solutions which are dependent upon collective experience of management team and experts in a firm and are highly tacit in nature. Therefore, managers try to avoid groupthink by designing efficient meetings including different techniques like brainstorming or Delphi techniques, and using better communication technologies (audio-visual presentations, tele-conferences, social media tools, e-mails, directories, etc.), and trying to sustain an open communication among group members (Pavey, 2014; Eaton, 2001).

\section{Discussions and Implications}

Due to technological advances and globalization, knowledge intensive services have become rapidly internationalized and network-oriented. Therefore, organizational communication is the ultimate way of sharing core values in today's multinational organizations and management teams. Teams in the global business environment are connected to each other as they continuously benefit from their cultural diversities and experiences. Therefore, organizational communication becomes a very important link among people who work at different levels and in different locations.

Groupthink theory provides important insights to today's managers who have various multi-functional roles and limited time for making successful decisions. As roles of group leaders or top managers increase and get diversified especially in KIS, their ability of team management and communication must be improved as well. Managers must take lessons from groupthink and know its consequences and the ways of preventing it.

Groupthink theory highlights the importance of situational context as an antecedent of groupthink symptoms. Organizational culture shaping culture of teams is an important indicator of team effectiveness. Teams in individualistic cultures may avoid groupthink more easily compared to collectivistic cultures whose members tend to be more cohesive. KIS whose team members are highly sophisticated and intelligent experts may adopt an adhocracy culture in which both individualistic and collectivistic cultures can be traced. In this approach, these innovative people can have an enough room for working alone as they would require, and to work in close coordination with others without sensing any hierarchy or authority above them.

This study offers several theoretical contributions and managerial implications. From the perspective of theory examination, this study posits that leadership as a very important 
antecedent condition needs to be investigated in more detail for KIS. The study also discusses the role of leadership style to avoid groupthink symptoms and provides suggestions to managers. Organizational culture could be a strong indicator of teams having groupthink symptoms. Therefore, future research should address how different types of organizational culture can be associated with groupthink symptoms more precisely. Especially for KIS which have multinational teams or team workers, organizational culture enhances the performance of teams and can be used as a diagnostic tool to assess their level of involvement to organizational norms and ethical issues.

\section{References}

Ahlfinger, N. R., \& Esser, J. K. (2001). Testing the groupthink model: Effects of promotional leadership and conformity predisposition. Social Behavior and Personality, 29(1), 31-42. http://dx.doi.org/10.2224/sbp.2001.29.1.31

Alvesson, M. (2004). Knowledge and knowledge-intensive works. Oxford; New York: Oxford University Press.

Antoinetti, R., \& Cainelli, G. (2007). Spatial Agglomeration, Technology and Outsourcing of Knowledge Intensive Business Services. Empirical Insights from Italy. International Journal of Services Technology and Management, 10(2/3/4) 273-298. http://dx.doi.org/10.1504/IJSTM.2008.022123

Baron, R. S. (2005). So Right It's Wrong: Groupthink and the Ubiquitous Nature of Polarized Group Decision Making. In Zanna, Mark P (Ed.) Advances in experimental social psychology (pp.219-253). San Diego: Elsevier Academic Press.

Berdie, D. R. (2003). Customer satisfaction success. Marketing Management, 12(2), 21-25. http://dx.doi.org/ 9318274

Cameron, K. S., \& Quinn, R. E. (2011). Diagnosing and changing organizational culture: Based on the competing values framework. 3rd Ed., San Francisco, CA: Jossey-Bass.

Carpenter, M. A., \&. Fredrickson, J. W. (2001). Top management teams, global strategic posture, and the moderating role of uncertainty. Academy of Management Journal, 44(1), 533-545. http://dx.doi.org/10.2307/AOM.3069366

Chen, Z., \& Lawson, R. B. (1996). Groupthink: Deciding with the leader and the devil. [Online] Available: http://www.thefreelibrary.com/Groupthink: Deciding with the leader and the devil.a018911798 (September 14, 2014)

Eaton, J. (2001). Management communication: The threat of groupthink. Corporate Communications, 6(4), 183-192. http://dx.doi.org/10.1108/13563280110409791

Haas, M. E., \& Banerje, M. (2008). Transnational teams in knowledge-intensive organizations. In Charles Wankel (Ed.) 21st Century Management: A Reference Handbook (pp. 11-34). Thousand Oaks, CA: Sage Publications . 
http://dx.doi.org/10.4135/9781412954006

Hausknecht, J. P., \& Trevor, C. O. (2011). Collective turnover at the group, unit, and organizational levels: Evidence, issues, and implications. Journal of Management, 37(1), 352-388. http://dx.doi.org/10.1177/0149206310383910

Hofstede, G. (1980). Culture's consequences: International differences in work-related values. Beverly Hills, CA: Sage Publications. http://dx.doi.org/0.1002/bs.3830270213.

Janis, I. L. (1972). Victims of groupthink. Hopewell, N.J: Houghton Mifflin Company.

Janis, I. L. (1982). Groupthink: Psychological studies of policy decisions and fiascoes. Boston: Houghton Mifflin. http://dx.doi.org/10.1009/0395317045

Kozlowski, S. J., \& Ilgen, D. R. (2006). Enhancing the effectiveness of work groups and teams. Psychological Science in the Public Interest, 7(3), 77-124. http://dx.doi.org/0.1111/j.1529-1006.2006.00030.x

Leana, C. R. (1985). A partial test of Janis' groupthink model: Effects of group cohesiveness and leader behavior on defective decision making. Journal of Management, 11(1), 5-17. http://dx.doi.org/10.1177/014920638501100102.

Littlejohn, S. W. (1992). Theories of human communication. $4^{\text {th }}$ ed.Belmont, CA: Wadsworth Publishing Company.

Lowendahl, B. (2000). Strategic management of professional service firms. Copenhagen, Denmark: Copenhagen Business School Press.

Meyer, E. (2010). The four keys to success with virtual teams. [Online] Forbes, Available: http://www.forbes.com/2010/08/19/virtual-teams-meetings-leadership-managing-cooperation. htm (September 14, 2014).

Miles, I, Kastrinos, N., Flanagan, K., Bilderbeek, R., Hertog, P., Huntink, W., \& Bouman, M. (1995). Knowledge-intensive business services: Users, carriers and sources of innovation. European Innovation Monitoring System (EIMS). EIMS Publication No. 15. Luxembourg. http://dx.doi.org/10.11565/cuocient.v2i1.25.

Miranda, S. M., \& Saunders, C. (1995). Group support systems: An organization development intervention to combat groupthink. Public Administration Quarterly, 19(2), 193-216.

Mitchell, D. H., \& Eckstein, D. (2009). Jury dynamics and decision-making: A prescription for groupthink. International Journal of Academic Research, 1(1), 163-169. http://dx.doi.org/10.7813/2075-4124.2009/1-1/A.24

Neck, C. P., \&. Moorhead, G. (1995). Groupthink remodeled: The importance of leadership, time pressure, and methodical decision-making procedures. Human Relations, 48(5), 537-556. http://dx.doi.org/10.1177/001872679504800505 
Pavey, S (2014). Groupthink. Decision making skills training from mindtools. [Online] Available: http://www.mindtools.com (August 8, 2014)

Schaeffer, L. D. (2002). The leadership journey. Harvard Business Review. Oct., 3-7. [Online] Available: http://hbr.org/2002/10/the-leadership-journey/ar/1 (July 23, 2014)

Sims, R. R. (1992). Linking groupthink to unethical behavior in organizations. Journal of Business Ethics, 11(9), 651-661.http://dx.doi.org/10.2307/25072319

Von Bergen, C. W., Sopher, B., \& Masters, R. (2001). Mismanagement by the golden rule. Industrial Management, 43(5), 6-12.

Woodruff, M. J. (1991). Understanding and combatting groupthink. Supervisory Management, $36(10), 8-12$.

Zieba, M. (2013). Knowledge-Intensive business services (KIBS) and their role in the knowledge-based [Online] Available: ftp://ftp.zie.pg.gda.pl/RePEc/gdk/wpaper/WP_GUTFME_A_7_Zieba.pdf (July 23, 2014)

\section{Copyright Disclaimer}

Copyright for this article is retained by the author(s), with first publication rights granted to the journal.

This is an open-access article distributed under the terms and conditions of the Creative Commons Attribution license (http://creativecommons.org/licenses/by/3.0/). 